\title{
Decision support system based on genetic algorithm and multi-criteria satisfaction analysis (MUSA) method for measuring job satisfaction
}

\author{
Ismahene Aouadni $^{1}$ - Abdelwaheb Rebai ${ }^{1}$
}

Published online: 8 March 2016

(C) The Author(s) 2016. This article is published with open access at Springerlink.com

\begin{abstract}
In this paper, we propose a Decision Support System based on the MUSA method and the continuous genetic algorithm in order to measure job satisfaction. The objective is to help organizations evaluate and measure their employees' satisfaction. Our study is composed of two parts. Firstly, we propose to combine continuous genetic algorithm and the MUSA method in order to obtain a robust solution of good performance. The aim of the development of this algorithm is to verify its efficiency regarding the classical MUSA algorithm. Therefore, we compare the result of continuous genetic algorithm with that of the MUSA algorithm. In the second part, we present our Decision Support Systems called "GMUSA System", it was developed in order to facilitate the applications and the use of the GMUSA tools and overcome the increasing complexity of managerial contexts. Our new system "GMUSA" is applied at the University of Sfax to measure teachers' job satisfaction.
\end{abstract}

Keywords Continuous genetic algorithm · Decision support system · Job satisfaction · MUSA method

\section{Introduction}

Although, job satisfaction was studied widely in psychology, it has no single definition but different opinions about it. Furthermore, it is not clear if there are specific measurement dimensions. The problems concerning a clear definition of job satisfaction lie mostly in the complexity of the topic, the subjectivity and the quality nature of the satisfaction concept (Grigoroudis and Siskos 2009).

Ismahene Aouadni

ismaheneawedni@gmail.com

Abdelwaheb Rebai

abdelwaheb.rebai@fsegs.rnu.tn

1 University of Sfax, MODILS, FSEG, 3018 Sfax, Tunisia 
Job satisfaction is the feeling of workers regarding their work (Smith et al. 1969). In addition, it shows the degree to which people like or dislike their jobs and the characteristics of their tasks (Koilias et al. 2012).

Fye and Mount (2007) define job satisfaction as the pleasurable or positive emotional state resulting from the appraisal of one's job or job experiences.

Several studies are interested in measuring the level of work satisfaction in order to satisfy the employees' needs (Aouadni et al. 2014).

Based on the literature review, there are many characteristics of job satisfaction such as earnings, worked hours, advancement, opportunity to find a job, opportunity to help others, relation with superiors and co-workers, professional development and promotion, independence and so on (Limin and Yonggang 2009; Super 1957).

The characteristics used as criteria for job selection are associated with job satisfaction; and can explain both productivity and the workers' intention to stay in the same job (Super 1957).

Several researches have been interested in studying teachers' job satisfaction. They indicate that job satisfaction is reduced by the school teachers experience burnout (Badri et al. 2013). Others were interested in studying the job resources, such as workload, students' behavior, parent-teacher relationship, cooperation with colleagues, support from the school leadership, autonomy and student-teacher relationship (Skaalvik and Skaalvik 2007; Spilt et al. 2011; Veldman et al. 2013).

Various studies focused on testing the social cognitive model of work satisfaction in teachers (Duffy and Lent 2009; Lent et al. 2011).

More other researchers have been studying the relationship between teachers' self-efficacy perceptions and job satisfaction level (Karabiyik and Korumaz 2014; Klassen and Chiu 2010). Mihaela (2014) studied how some personality traits—extroversion-introversion and nervousness of teachers are related to different facets of job satisfaction. Anghelache (2014) revealed that teachers from the rural area have a higher level of job satisfaction than those of the urban areas. Demirel (2014) examined the relationship between job- and life satisfaction among teachers. Guglielmi et al. (2014) confirm that there is a subsequent mediation of the organizational identification and work engagement between opportunities of professional and job satisfaction. Treputtharat and Tayiam (2014) indicate that the school climate affects job satisfaction of teachers.

Aslan et al. (2014) examined the relationships between job satisfactions, organizational support, academics employer relations and organizational citizenship behavior.

Lee and Nie (2014) explained how the four dimensions of psychological empowerment might differentially affect teachers' job satisfaction.

Other researchers are interested in studying the relationship between racial diversity of teachers and students and the job satisfaction of teachers (Ingersoll and May 2011a; Farkas et al. 1990; McGrady and Reynolds 2012; Mueller et al. 1999; Renzulli et al. 2011; Downey and Pribesh 2004; Stearns et al. 2014).

The criteria used in many researches to study the teacher's job satisfaction are the emotional exhaustion, job demands, control over one's work environment, school type, stress, tenure, competence, organizational culture, demographic variables and social support (Badri et al. 2013).

The teachers' job attitudes influence the scientific research and training and are intrinsically linked with their own individual job satisfaction condition (Limin and Yonggang 2009).

It is necessary to measure and evaluate the university professors' work satisfaction because it has an effective role in establishing the level of teaching and research, increasing academic competitiveness, bringing and keeping accomplished people (Aouadni et al. 2014). 
In order to evaluate the university teachers' job satisfaction, we need to analyze their attitudes to work, identify the existing problems and put forward improved measures (Limin and Yonggang 2009).

In the educational settings, job satisfaction is defined as the teachers' affective reactions to work or to the teaching role (Skaalvik and Skaalvik 2011; Zembylas and Papanastasiou 2004).

As teachers' satisfaction or dissatisfaction with their work lives could have crucial impacts on their teaching quality and their students' there is a need to pay greater attention to teachers' job satisfaction in research and practice (Lee and Nie 2014).

Most of these studies provided linear, descriptive, and exploratory methods of analysis (Badri et al. 2013). Recently, Aouadni et al. (2014) have applied MUSA to measure teachers' job satisfaction at the university.

The MUSA method has played an important role in the development of preference disaggregation models. It has been developed in order to measure and analyze the customer's satisfaction (Grigoroudis et al. 2002).

This method is used for the assessment of a set of marginal satisfaction functions in such a way that global satisfaction criterion becomes as consistent as possible with the customers' judgments. Thus, the main objective of the method is the aggregation of individual judgments into a collective value function (Grigoroudis et al. 2002).

The success of MUSA is witnessed by many applications in different fields such as, the banking sector (Grigoroudis et al. 2002), agricultural marketing (Siskos et al. 2001) and transportation-communication sector (Grigoroudis and Siskos 2004), job satisfaction (Aouadni et al. 2014), websites quality (Grigoroudis et al. 2008).

Joao et al. (2010) proposed a method that aggregates the individual customer's satisfaction criteria into an overall value function, but it makes use of a dummy variable regression technique with additional constraints. For the same input information, the outputs of the proposed method are more stable than those of MUSA and the differences observed enabled us to have a deeper knowledge on how to handle the input preference information provided by the customers. Moreover, contrary to MUSA, they proposed to apply more than one regression technique, starting with a dummy variable regression technique employing the least squares approach and then iteratively using a robust method of regression such as M-regression.

Other publications which are interested in ameliorating the MUSA such as the MUSA-INT proposed by Angilella et al. (2014), also take into account positive and negative interactions among the criteria, similarly to the multi-criteria method UTAGMS-INT. In addition, the MUSA-INT takes into account a set of utility functions representing customers' satisfaction, by adopting the robust ordinal regression methodology (Angilella et al. 2014).

In our study, we are interested in ameliorating the algorithm of the MUSA method. This method applies a heuristic method for near optimal solutions search. This algorithm is based on the near optimal solution because the optimal solutions are not the most interesting, given the uncertainty of the model parameters and the preferences of the decision-maker (Van De Panne 1975) and the number of the optimal or near optimal solutions is often huge. Therefore an exhaustive search method (reverse simplex, Manas-Nedoma algorithms) requires a lot of computational effort.

Siskos (1985) indicated that the algorithm (reverse simplex, Manas-Nedoma algorithms) has many limits such as large computer memory storage, long computation time, lack of a strong robustness and difficult implementation.

Therefore, it is quite hard to find the optimal (or the near-optimal) solution with reasonable computation time and good quality. 
The MUSA method depends on continuous variables, for this reason, a continuous genetic algorithm methodology is implemented.

Firstly, this paper proposes a Genetic Multi-criteria Satisfaction Analysis (GMUSA) method in order to ameliorate the classical MUSA algorithm.

Genetic algorithms are the most widely used computational models of evolution in artificial intelligence. These decentralized models provide a basis for the understanding of many other systems and phenomena in the world.

If the parameters of GAs used in optimization problems are correlated with each other, the continuous genetic algorithm (CGA) is preferable in this case (Arqub and Abo-Hammour 2014).

The MUSA method depends on continuous variables, for this reason, a continuous genetic algorithm methodology is implemented. The objective is to obtain a robust solution of good performance.

The Decision Support Systems (DSS) help the DM to make the best choice that integrates its preferences. Therefore, some DSS work with the subjective perspectives, judgments, beliefs, and preferences of the DM. In a more precise way, the DSSs are developed to achieve many roles such as organizing the overflow of information and knowledge and helping the DM in elucidating his/her judgement and preferences (Razmak and Aouni 2015).

In fact, the DSS is "an interactive system that assists managerial decision makers to use data and models to solve semi-structured and unstructured problems" (Qian et al. 2004).

The type of semi-structured problem where DSS is successful frequently arises in logistics and operations management problems and many early DSS applications were in fields such as vehicle routing and production scheduling (Eom and Lee 1990). DSS has been used for human resource management (HRM) problems, in order to solve the problem of personnel scheduling (Ernst et al. 2004). A number of DSS applications were also developed to deal with other areas of human resource management, for example, productivity improvement (Young 1989), performance analysis (Ntuen et al. 1994), career management (Bellone et al. 1995), and personnel selection problem (Ntuen and Chestnut 1995; Nussbaum et al. 1999).

The Multi-Criteria Decision Support System (MCDSS) helps the skills evaluator which a candidate's professional experience is analyzed and examined for each of his/her previous jobs, and a global value is assessed for each skill, taking also into account the years of employment in each one of the previous professional fields. The skills evaluator adapted to the educational system of Greece is a software tool that implements the proposed multicriteria evaluation method (Razmak and Aouni 2015).

Another author represented a DSS for a large scale problem of assigning workers to jobs according to multi criteria in large organizations in order to be able to assign a personnel, according to their capabilities (Constantopoulos 1989). In addition all the qualifications of the candidates for accreditation in information technology, which have been acquired through any type of learning were added (Siskos et al. 2007).

For the past two decades, Decision Support System (DSS) for MCDM has been widely applied to overcome the increasing complexity of managerial contexts.

Razmak and Aouni (2015) precise that over the years, the integration of the MCDA tools into a model base of DSS has provided decision makers with powerful capabilities in analyzing, exploring, and comparing a set of alternatives.

Also, they indicate that the MCDSS has been used since 2005 than in the 1990s. The number of papers written on MCDSS has increased over the last 10-year period.

AHP and Utility Additive (UTA) methods are the two-most used methods in DSS with 15 papers for UTA and 18 for AHP (Razmak and Aouni 2015). 
Grigoroudis and Siskos (2003) developed decision support systems for the MUSA method in order to evaluate a customer's satisfaction.

Almost the MCDSS is composed of three main components: (a) the Data Subsystem, (b) the Model Subsystem and (c) the Dialogue Subsystem.The Data Subsystem is used for the data management (store, update, restore and process). The Model Subsystem includes the software that implements the multicriteria approach in a structural form. The Dialogue Subsystem provides the tools for the communication interface between the DM and the system (Siskos and Spyridakos 1999).

Recently, some studies have presented the concept of Intelligent Multi-criteria Decision Support Systems and its application to real decision-making contexts (Deng et al. 2010; Wibowo 2011). In general, these studies highlight the contribution of the DSS as a support for the utilization of the MCDA methods to deal with some complex decision-making situations.

For this reason, in the second part of this paper, we develop a decision support system called "GMUSA" in order to facilitate the applications and the use of the GMUSA tools.

Therefore, a DSS for GMUSA method is applied at the University of Sfax in order to measure the satisfaction of the 100 teachers through a questionnaire which consists of 8 criteria. The collected data are the same used by Aouadni et al. (2014).

After a general description of MUSA method, continuous genetic algorithm and Decision support system, we present DSS “GMUSA" in order to measure the university teachers' job satisfaction.

\section{Basic concepts}

\subsection{MUSA method}

The MUSA method was initially developed to measure customers' satisfaction. It is based on the aggregation of individual judgments into a collective value function, because the customers' global satisfaction depends on a set of criteria representing service characteristic aspects (Grigoroudis and Siskos 2002).

The MUSA method is an ordinal regression used for the assessment of a set of marginal satisfaction functions in such a way that the global satisfaction criterion becomes as consistent as possible with individual's judgments (Grigoroudis and Siskos 2002).

According to the survey, each teacher is asked to express his/her global satisfaction and his/her satisfaction with regard to a set of discrete criteria on a predefined ordinal satisfaction scale. The MUSA method is used in order to minimize the sum of deviations between global satisfaction evaluated by teachers and the one resulting from their multi-criteria satisfaction evaluation (Koilias et al. 2012).

The basic elements of MUSA method:

$\mathrm{j}=(1, \ldots, \mathrm{M})$ is the set of teachers,

$\mathrm{i}=(1, \ldots, \mathrm{n})$ is the number of criteria

$\mathrm{q}=\left(1, \ldots, \mathrm{n}_{\mathrm{i}}\right)$ is the number of sub-criteria

U: Teacher's global satisfaction

$\mathrm{m}=(1, \ldots, \alpha)$ : Number of global satisfaction

$\mathrm{u}^{m}$ : The mth global satisfaction level

Vi: Client's satisfaction according to the ith criterion $(i=1,2, \ldots, n)$

$\mathrm{k}=\left(1, \ldots, \alpha_{\mathrm{i}}\right)$ : Number of satisfaction level for the ith criterion

$v_{i}^{k}$ : The kth satisfaction level of the ith criterion 
$\mathrm{U}^{*}$ : Value function of $\mathrm{U}$

$u^{*}$ : The value of um satisfaction level

$\mathrm{V}_{\mathrm{i}}^{*}$ : The value function of $\mathrm{V}_{\mathrm{i}}$

$\mathrm{V}_{\mathrm{i}}^{\mathrm{k} *}$ : Value of the $\mathrm{V}_{\mathrm{i}}^{*}$ satisfaction level

$b_{i}$ : The weight of ith criterion

$\mathrm{n}_{\mathrm{i}}$ : Number of sub-criteria for the ith criterion

$\mathrm{V}_{\mathrm{iq}}$ : Client's satisfaction for the qth sub-criterion of the ith criterion $(\mathrm{q}=1,2, \ldots, \mathrm{ni}, i=$ $1,2, \ldots, \mathrm{n})$

$\propto_{\mathrm{iq}}$ : Number of satisfaction levels for the qth sub-criterion of the ith criterion

$\mathrm{V}_{\mathrm{iq}}^{\mathrm{k}}$ : The kth satisfaction levels for the qth sub-criterion of the ith criterion

$\mathrm{V}_{\mathrm{iq}}^{*}$ : Value function of $\mathrm{V}_{\mathrm{iq}}$

$\mathrm{V}_{\mathrm{iq}}^{* \mathrm{k}}$ : Value of the $\mathrm{V}_{\mathrm{iq}}^{*}$ satisfaction level

$b_{i q}$ : Weight for the qth sub-criterion of the ith criterion

$\mathrm{z}_{\mathrm{m}}\left(\mathrm{u}^{* \mathrm{~m}+1}-\mathrm{u}^{* \mathrm{~m}}\right) \in[0,100]$ : The marginal utility of global satisfaction functions for each criterion.

$\mathrm{w}_{\mathrm{ik}}=\left(\mathrm{b}_{\mathrm{i}} \mathrm{v}_{\mathrm{i}}^{* \mathrm{k}}+1-\mathrm{b}_{\mathrm{i}} \mathrm{v}_{\mathrm{i}}^{* \mathrm{k}}\right) \in[0,100]$ : The marginal utility partial satisfaction functions for each criterion.

$\mathrm{w}_{\mathrm{ik}}=\left(\mathrm{b}_{\mathrm{i}} \mathrm{b}_{\mathrm{iq}} \mathrm{v}_{\mathrm{iq}}^{* \mathrm{k}+1}-\mathrm{b}_{\mathrm{i}} \mathrm{b}_{\mathrm{iq}} \mathrm{v}_{\mathrm{iq}}^{* \mathrm{k}}\right) \in[0,100]$ : The marginal utility partial satisfaction functions for each sub-criterion.

$\sigma_{\mathrm{ij}}^{+}$and $\sigma_{\mathrm{ij}}^{-}$are over- and under-estimation of errors for every teacher's utility function respectively The global and partial marginal utility function $\left(\mathrm{z}_{\mathrm{m}}, \mathrm{w}_{\mathrm{ik}}, \mathrm{w}_{\mathrm{iqk}}\right)$ are obtained by solving the following LP problem:

$$
\operatorname{Min} F=\sum_{j=1}^{M} \sigma_{j}^{+}+\sigma_{j}^{-} \sum_{j=1}^{M} \sum_{i=1}^{n} \sigma_{j i}^{+}+\sigma_{j i}^{-}
$$

Subject to

$$
\begin{aligned}
& \sum_{i=1}^{n} \sum_{k=1}^{t_{j i}-1} w_{i k}-\sum_{m=1}^{t_{j}-1} z_{m}-\sigma_{j}^{+}+\sigma_{j}^{-}=0 \\
& \sum_{q=1}^{n_{i}} \sum_{k=1}^{t_{j i q}-1} w_{i q k}-\sum_{k=1}^{t_{j i}-1} w_{i k}-\sigma_{j i}^{+}+\sigma_{j i}^{-}=0 \text { for } i=1,2 \ldots, n \text { and } j=1,2, \ldots, M, \\
& \sum_{i=1}^{n} \sum_{q=1}^{n_{i}} \sum_{k=1}^{\alpha-1} w_{i q k}=100 \\
& \sum_{m=1}^{\alpha} z_{m}=100, \\
& \sum_{i=1}^{n} \sum_{k=1}^{\alpha_{i}-1} w_{i k}=100, \\
& z_{m}, w_{i k}, w_{i q k}, \sigma_{j}^{+}, \sigma_{j}^{-} \geq 0 \forall m, i, j, k
\end{aligned}
$$

where $t_{j}$ and $t_{j i}$ are the judgment of the jth teacher for global and partial satisfaction with $\mathrm{u}^{\mathrm{tj}} \in \mathrm{Y}=\left\{\mathrm{u}^{1}, \mathrm{u}^{2}, \ldots, \mathrm{u}^{\mathrm{tj}}, \ldots, \mathrm{u}^{\propto}\right\}$ and $\mathrm{v}_{\mathrm{i}}^{\mathrm{t}_{\mathrm{ji}}} \in \mathrm{V}_{\mathrm{i}}=\left\{\mathrm{v}_{\mathrm{i}}^{1}, \mathrm{v}_{\mathrm{i}}^{2}, \ldots, \mathrm{v}_{\mathrm{i}}^{\mathrm{t}_{\mathrm{ji}}}, \ldots, \mathrm{v}_{\mathrm{i}}^{\alpha_{\mathrm{i}}}\right\}$ 
The model variables are calculated according to the following formulas:

$$
\begin{aligned}
& \mathrm{b}_{\mathrm{i}}=\sum_{\mathrm{t}=1}^{\alpha_{\mathrm{i}}-1} \mathrm{w}_{\mathrm{it}} / 100 \text { for } \mathrm{i}=1,2, \ldots, \mathrm{n}, \\
& \mathrm{u}^{* \mathrm{~m}}=\sum_{\mathrm{t}=1}^{\mathrm{m}-1} \mathrm{z}_{\mathrm{t}} \text { for } \mathrm{m}=2,3, \ldots, \alpha, \\
& \mathrm{v}_{\mathrm{i}}^{* \mathrm{k}}=100 \sum_{\mathrm{t}=1}^{\mathrm{k}-1} \mathrm{w}_{\mathrm{it}} / \sum_{\mathrm{t}=1}^{\alpha-1} \mathrm{w}_{\mathrm{it}} \mathrm{i}=1,2, \ldots, \mathrm{n} \text { and } \mathrm{k}=2,3, \ldots, \alpha_{\mathrm{i}} \\
& \mathrm{b}_{\mathrm{ij}}=\sum_{\mathrm{t}=1}^{\alpha_{\mathrm{iq}}-1} \mathrm{w}_{\mathrm{iqt}} / \sum_{\mathrm{t}=1}^{\alpha_{\mathrm{i}}-1} \mathrm{w}_{\mathrm{ijt}}, \\
& \mathrm{v}_{\mathrm{ij}}^{* \mathrm{k}}=100 \sum_{\mathrm{t}=1}^{\mathrm{k}-1} \mathrm{w}_{\mathrm{ijt}} / \sum_{\mathrm{t}=1}^{\alpha_{i j}-1} \mathrm{w}_{\mathrm{iqk}} \text { for } \mathrm{i}=1,2, \ldots, \mathrm{n} \text { and } \mathrm{k}=2,3, \ldots, \alpha_{\mathrm{iq}}
\end{aligned}
$$

In order to solve the linear programming the MUSA method applies the heuristic (reverse simplex and Manas-Nedoma algorithms) which has many limits such as large computer memory storage, long computation time, lack of a strong robustness and difficult implementation. In order to avoid these limits, we propose to use the genetic algorithm.

Since the parameters of GAs are correlated with each other, the continuous genetic algorithm (CGA) is preferable in this case (Arqub and Abo-Hammour 2014).

The MUSA method depends on continuous variables, for this reason a continuous genetic algorithm methodology is implemented. In the next section, we present briefly the continuous genetic algorithm.

\subsection{Continuous genetic algorithms}

The Genetic algorithms (GAs) are part of the evolutionary ones. The GAs are based on a process of nature, namely, Darwinian evolution. The purpose of using such methods is not to find an exact analytical solution but to find the best possible solution in a fixed amount of time.

John Holland laid the groundwork for the GAs. Then, Goldberg (1989) used them to solve the optimization problems. In the GAs, a population of individuals reproduces according to their fitness in an environment. The population of individuals, coupled with stochastic recombination operators combine to perform an efficient domain-independent search strategy that makes few assumptions about the search space.

The GAs transform a set of individuals each with an associated fitness value, into a new population (next generation) using operations like the Darwinian principle of reproduction and survival of the fittest and after naturally occurring genetic operation.

The general characteristics of the theory of the GAs are widely accepted and applied, which result in good solutions for the different types of problems in different disciplines. The GAs are very versatile in which the based techniques accept discrete and/or continuous variables (Arqub and Abo-Hammour 2014).

If the parameters of GAs using in optimization problems are correlated with each other, then the continuous genetic algorithm (CGA) is preferable in this case (Arqub and AboHammour 2014). 
The CGA algorithm starts with an initial population randomly generated and derives to the best solution by applying genetic operators (Arqub and Abo-Hammour 2014).

In our research we use the continuous genetic algorithms because the linear programming of MUSA method depends on continuous variables such as $\mathrm{w}_{\mathrm{ij}}$ and $\mathrm{z}_{\mathrm{m}}$. The value of this variable is between 0 and 100 and the total value is 100 .

\subsection{Decision support systems}

The "decision support systems" was first coined by P.G.W. Keen, a British Academic working in the United States of America in 1970. Keen and Scott Morton published a book entitled "decision support system: an organizational perspective" in 1978.

The DSS was a new philosophy of how computers could be used to support managerial decision-making. This philosophy embodied unique and exciting ideas for the design and implementation of such systems.

The Decision support systems (DSS) are technologies that provide the right knowledge to the right decision makers at the right times in the right representations at the right costs. The DSS is a computer-based system that represents and processes knowledge in a way that makes the decision making more productive, agile, innovative, and/or reputable (Bernus et al. 2008).

The Decision Support Systems existed to help people make decisions but they do not make decision by themselves (Mallach 1994).

Decision Support Systems (DSS) are defined as model-based sets of procedures for processing data and judgments to assist a manager in his decision-making. In other words, DSS are interactive computer-based systems that support Decision Makers (DMs) to solve problems and make decisions.

DSS are commonly used to inform problem solving and assist decision-making processes by providing tools for combining quantitative data and qualitative knowledge/perceptions, and for processing this information in order to present, compare and rank planning alternatives and, ultimately, select the one that satisfies the established decision criteria (Carsjens and Ligtenberg 2007).

In general, the decision support systems (DSSs) provide support for the decision makers by bringing together human judgment and computerized information in an attempt to improve the effectiveness of decision-making (Turban and Aronson 1998).

Due to the diversity and complexity of the attributes, their interrelationships, and the volume of information involved, the system to be used in the analysis must be efficient, effective and easy to use. The linkage of Information Systems (IS) and formal decision support models whose attributes are structured in a hierarchical structure is a promising way to analyze university teacher's job satisfaction.

Decision support systems consist of three main components, namely a database, software system and user interface.

\subsubsection{DSS database}

The data of DSS are from various sources, such as internal data from the organization, the data generated by different applications, and the external data obtained from the Internet, etc. A DSS database is a collection of data organized for easy access and analysis. It can be a small database or a standalone system or a huge data warehouse supporting the information needs of an organization. 


\subsubsection{DSS software system}

The DSS software is a collection of software tools that are used for data analysis or a collection of mathematical and analytical models. It is composed of various mathematical and analytical models that are used to analyze the complex data, thereby producing the required information. A model predicts the output on the basis of different inputs or different conditions, or finds out the combination of conditions and the input required to produce the desired output.

Some of the commonly used mathematical and statistical models are:

Statistical Models They contain statistical functions, such as mean, median, mode, deviations etc.

Sensitivity Analysis Models These are used to provide answers to what-if situations occur frequently in an organization.

Optimization Analysis Models They are used to find an optimum value for a target variable under given circumstances. They are widely used for making decisions related to the optimum utilization of resources in an organization.

Forecasting Models They use various forecasting tools and techniques, including the regression models, time series analysis, and market research methods etc., to make statements about the future or predict something in advance. They provide information that helps in analyzing the business conditions and making future plans. These Systems are widely used for forecasting sales.

Backward Analysis Sensitivity Models Also known as goal seeking analysis, the technique followed in these models is just opposite to the technique applied in sensitivity analysis models.

\subsubsection{DSS user interface}

An effective user interface is the most critical component of any type of decision support systems. It is an interactive graphical interface which makes the interaction between the DSS and its users easier. It displays the results (output) of the analysis in various forms, such as texts, tables, charts or graphics.

\section{University teachers' job satisfaction application}

The development of any university depends on the level of the employee satisfaction and especially the teachers because the university teachers' job satisfaction has a constructive role in raising the level of teaching and research, enhancing academic competitiveness, attracting and retaining talented people.

Job satisfaction includes the attitude, feelings and personal preferences of the employees and the interest in their jobs (Chen 2008; Lambert et al. 2007).

In other words, research indicates that job satisfaction is significantly related to life satisfaction. Hence, the organization must discover the preferences, the desire and satisfaction levels of their employees.

It is necessary to measure job satisfaction to assess trends in the employees' attitudes or reactions to a new policy or organizational intervention. Measuring job satisfaction can have a diagnostic purpose, which identifies those aspects of the job with which employees are dissatisfied.

Our study was conducted at the University of Sfax in order to measure the satisfaction of the 100 teachers through a questionnaire which consists of 8 criteria. 
A five-point Likert-type scale ("Very Dissatisfied", "Dissatisfied", "neither", "Satisfied", "Very Satisfied") was used for all the criteria and sub-criteria to evaluate job satisfaction. In the next section, we present the results of the application GMUSA system in the University of Sfax.

\subsection{Description of GMUSA system}

\subsubsection{Genetic MUSA algorithm}

The CGA proposed in this work consists of the following steps.

3.1.1.1 Initialization In this step, an initial population must be randomly generated, so that each chromosome represents a feasible solution to the problem.

Two matrices represent the population, the matrix of wij (marginal function of partial satisfaction) and that of $\mathrm{z}_{\mathrm{m}}$ (marginal function of global satisfaction) with each row in the matrix being a $1 \times \mathrm{N}_{\mathrm{var}}$ array (chromosome) of continuous values. All variables are normalized to have values between 0 and 100 .

3.1.1.2 Selection In the selection process, we choose two parents from the population and crossed them by using a fitness function. The Chromosomes are selected to be parents for the crossover. The problem is how to select these chromosomes. According to Darwin's theory of evolution, the best ones survive to create a new offspring.

The method used for the selection is decomposed in the following steps:

Step 1: Function coefficient (enss, w, z) returns 4 matrices. The first matrix $\mathrm{w}_{\mathrm{ij}}$ that influence $\sigma^{+}$, the second $\mathrm{w}_{\mathrm{ij}}$ that influences $\sigma^{-}$, the third matrix $\mathrm{z}$ that influence $\sigma^{+}$and finally the matrix $\mathrm{z}$ that influence $\sigma^{-}$.

Step 2: Difference matrix returns the difference between the coefficient matrices.

Step 3: Choose the min and the max in Difference matrix in order to cross.

3.1.1.3 Crossover operators After choosing two individuals from the current population as parents, P1 and P2, to generate two children E1 and E2 and choose the frontier f, we randomly generate one position in order to cross.

This operator will be conducted as follows:

Step 1: Choosing two individuals from the current population as parents, P1 and P2, to generate two children E1 and E2 and choose the frontier $\mathrm{f}$

Step 2: Generating one position randomly

Step 3: crossing: We adopt the following algorithm in order to have a new chromosome which decomposes in the following way:

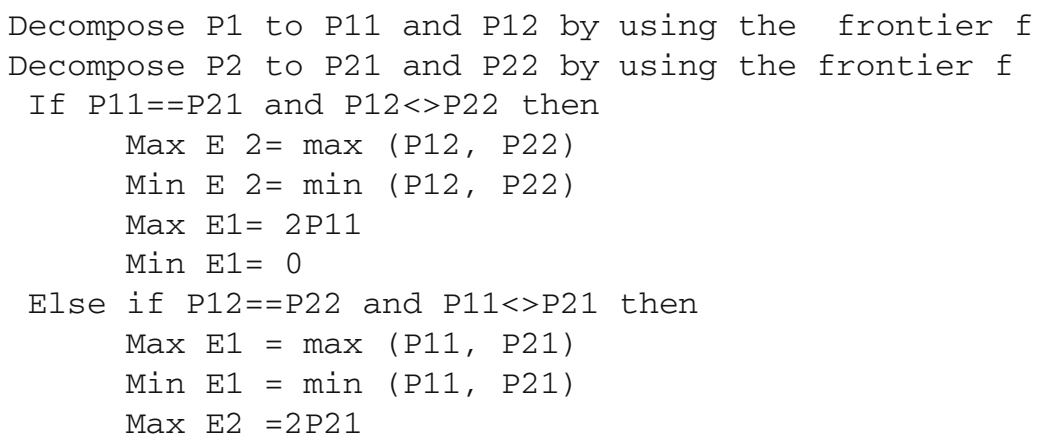




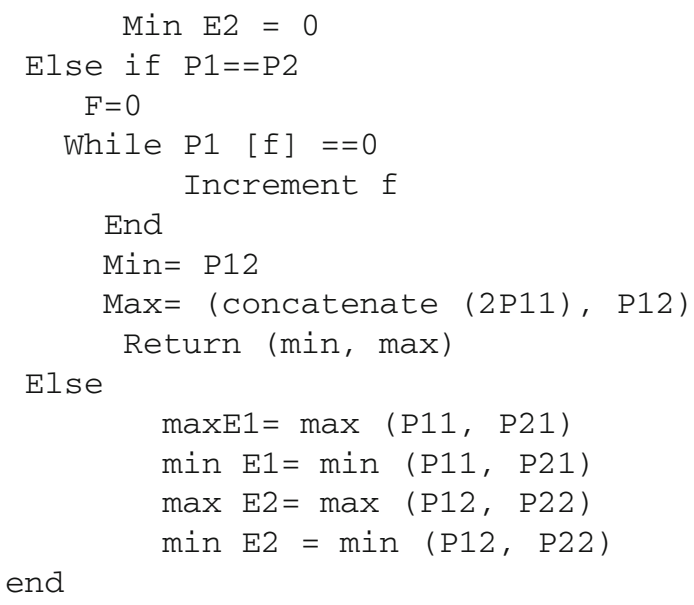

3.1.1.4 Mutation operator The Chromosomes obtained after the crossover function will undergo a mutation process. The mutation operator algorithm decomposes in the following way.

Choose chromosomes $\mathrm{w}_{\mathrm{ab}}$ and $\mathrm{w}_{\mathrm{cd}}$ in which $\mathrm{w}_{\mathrm{ab}} \neq \mathrm{w}_{\mathrm{cd}}$ from the matrix $\mathrm{w}_{\mathrm{ij}}$

- While P1 [index] == P2 [index] Increment index

- While P1 [index] <> P2 [index] Switch P1 [index] and P2 [index] for the new W

The same algorithm is of the global satisfaction function.

3.1.1.5 Fitness function The fitness function is the objective value to minimize the sum of errors

$$
\operatorname{Min} F=\sum_{j=1}^{M} \sigma_{j}^{+}+\sigma_{j}^{-} \sum_{j=1}^{M} \sum_{i=1}^{n} \sigma_{j i}^{+}+\sigma_{j i}^{-}
$$

3.1.1.6 Convergence criteria The genetic algorithm stops after a priori fixed number of generations. It is fixed at 100,000 generations.

To implement our algorithm, we use php5 released and powered by the new Zend Engine II. PHP 5 includes new features such as the improved support for the object-oriented programming, the PHP Data Object (PDO) extension and the numerous performance enhancements.

\subsubsection{GMUSA architectures}

In general, the decision support system (DSS) improves the effectiveness of decision-making by bringing together judgment human and computerized information (Turban and Aronson 1998).

A Decision support system is composed of three components, such as a database, model and user's interface (Fig. 1).

3.1.2.1 DSS database The data may be read from an external text file or may be entered directly to the program. In order to enter directly a data to the system, the user (teacher in our application) must create an account and complete the questionnaire and sent it. All the steps are presented as follows: 


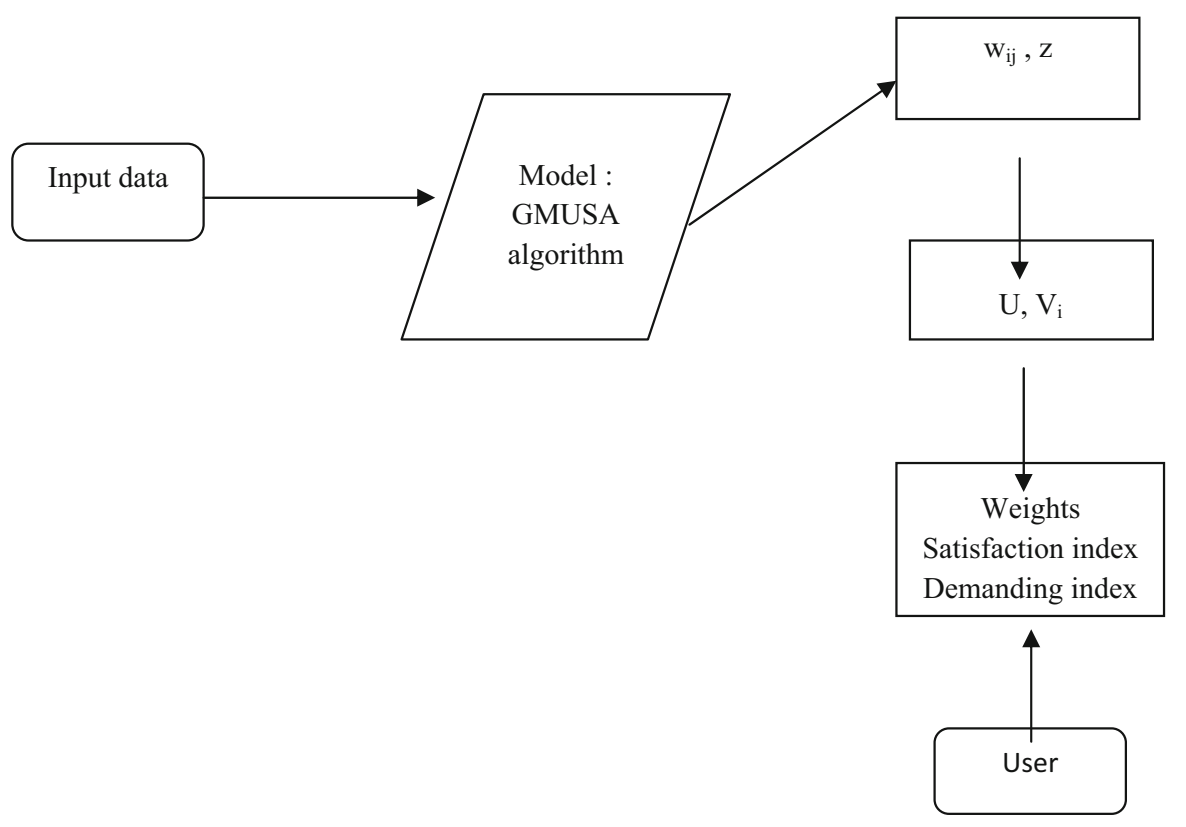

Fig. 1 Structure of DSS

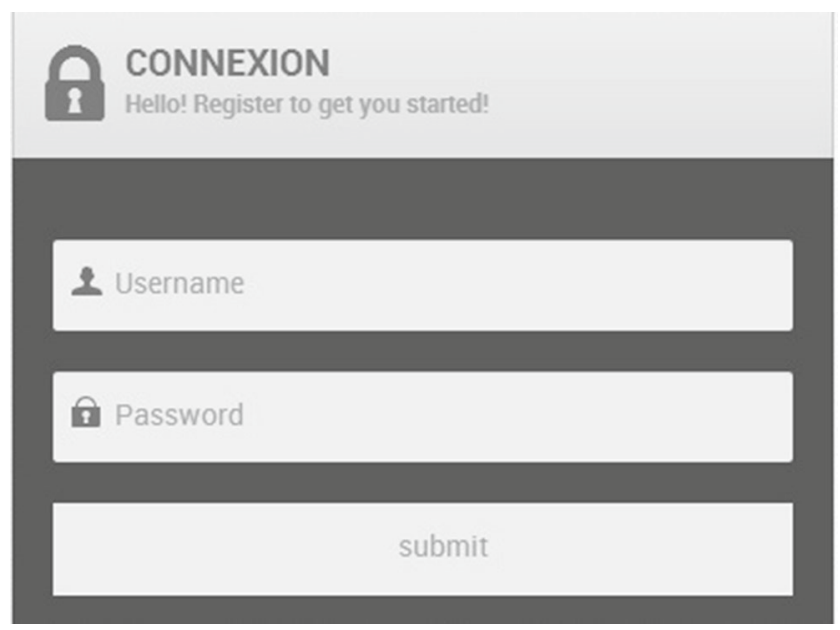

Fig. 2 Create an account

Step 1: Create an account

In order to answer the questionnaire, each teacher must create an account by entering a username and login. When going through this step, the response of each teacher is registered in the database of our system (Fig. 2).

Step 2: Answering the questionnaire

When the teacher has an account, he answers the questions by checking the appropriate choice.

Step 3: Submitting the answers of the questionnaire. 
3.1.2.2 DSS Software System The DSS software is composed of various mathematical and analytical models that are used to analyze the complex data, there by producing the required information. Our system is composed of GMUSA algorithm described in previous section.

3.1.2.3 DSS User Interface The user interface is the means by which a person controls a software application. The role of a user is:

a. To control a software application such as the algorithms

b. To be responsible of any change in the algorithms and the design of systems

c. Diffusion and Interpretation of results.

The user must create an account to access the results. All the steps are presented as follows:

Step 1: To enter the username and login of the decision maker

Step 2: When the user enters a username and login, he can access the results.

Step 2.1: In order to access the results, the decision maker clicks on the "questionnaire" then the "questionnaire list" and finally the "details". A window containing the questionnaire responses of teachers is displayed.

Step 2.2: If he wants to create a new questionnaire, the user clicks on the icon "new questionnaire".

In this step, you can add criteria and sub-criteria of your choice.

To save the new criteria or/and sub-criteria in the database of the system, you must submit it by clicking on the icon "submit".

Step 3: Accessing the results

In order to access the results $\left(\mathrm{w}_{\mathrm{ij}}, \mathrm{z}\right)$ of the determinist model "genetic multi-criteria satisfaction method", you have to click on icon "statistic".

After that, you can see the result of each criterion by clicking on the "statistic" in front. Then the results of each criterion are be displayed, they include:

- Response frequencies in each criterion

- Global Satisfaction index

- Weights of each criteria

- Satisfaction index

- Demanding index

\subsubsection{Genetic MUSA result}

In order to compare the GMUSA and the MUSA methods, we need to compare the objective value of both methods.

The objective value is the minimization of the sum of errors $\left(\sigma^{+}, \sigma^{-}\right)$. The result of GMUSA is better than that of MUSA method proposed by Aouadni et al. (2014). For all the criteria and global satisfaction, the error was decreased. The differences between both methods are allowable/acceptable (Fig. 3).

The computational results that we have conducted show that our approach help obtain significant improvements over the existing results. This improvement is materialized by the reduction of the objective function.

\subsubsection{Global satisfaction result}

The average global satisfaction index is very low (28\%) because the teachers are not satisfied with the most important criteria of the offered compensation $(30,4 \%)$ and resources $(40 \%)$ (Fig. 4). 


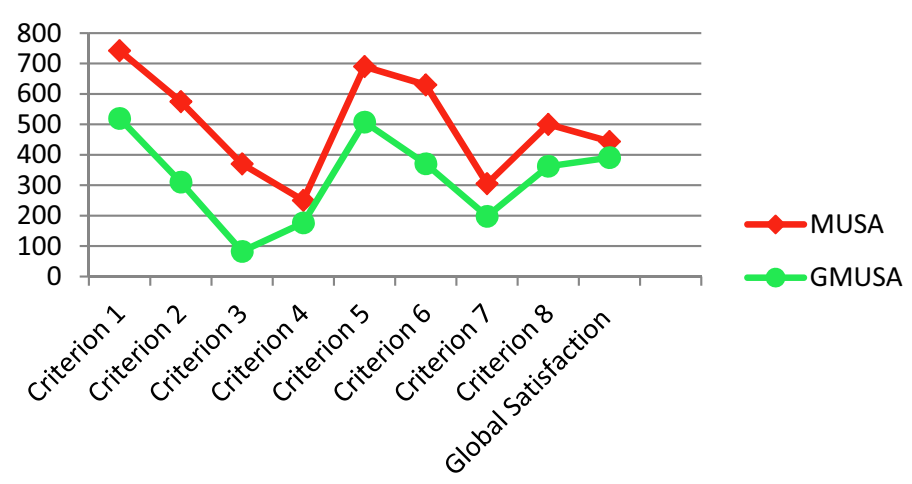

Fig. 3 Objective value

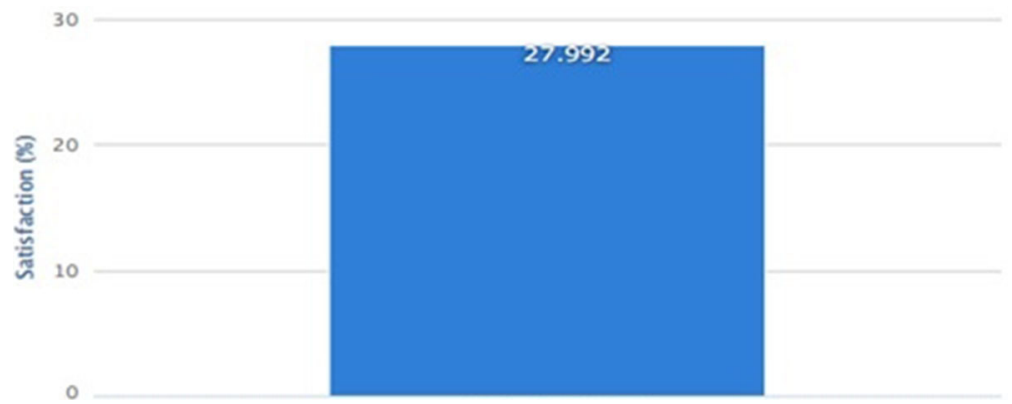

Fig. 4 Global satisfaction

\title{
Weights
}

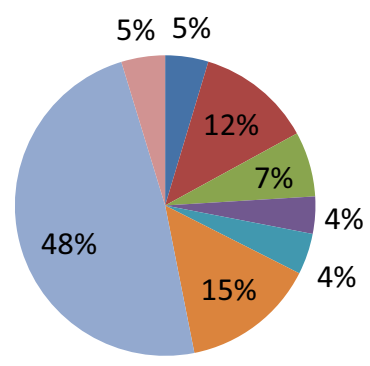

\author{
- University administration \\ Student interaction \\ Professional \\ development \\ Safety
}

Fig. 5 Weights of criteria

\subsubsection{Criteria result}

Regarding the satisfaction dimensions, the criterion of the compensation seems to be the most important (weight $48.39 \%$ ), while at the same time, it presents the lowest satisfaction index $(30.41 \%)$ but with a high demanding index $(91.73 \%)$.

The rest of the criteria have high satisfaction indices (56-89.93\%) compared to the global satisfaction level, so they have non-significant improvement margins. (See Figs. 5, 6, 7) 


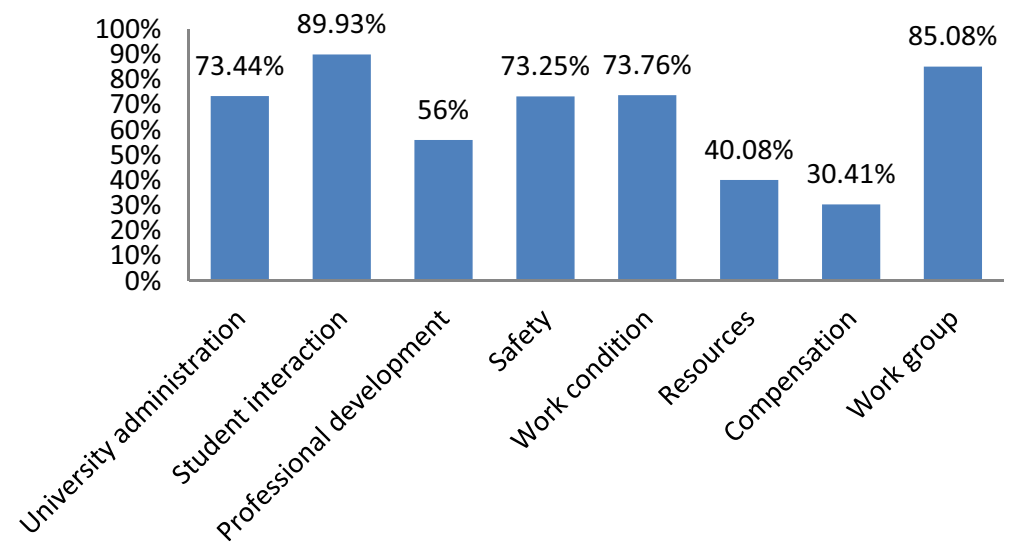

Fig. 6 Satisfaction index of criteria

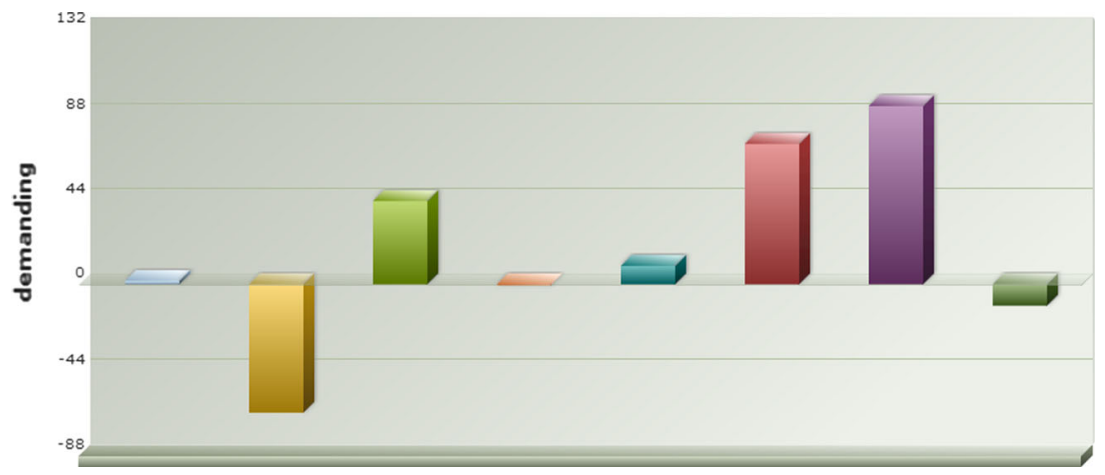

Fig. 7 Demanding index of criteria

\section{Conclusion}

In order to help any organization evaluate and measure job satisfaction for their employees and that of their customers, we developed a decision support system based on MUSA method and genetic algorithm.

The choice of the GAs is made to exceed the limits of the MUSA algorithm. The results of the new method show that the suggested algorithms produce good quality solutions by the reduction of the objective function.

Our approach was applied at Sfax University to measure the teachers' job satisfaction. The global satisfaction of teachers was reduced to $28 \%$ compared to the result of the classic MUSA. In addition, the weights of criteria were changed where the most important criterion in the GMUSA method is the "compensation" and not "Student interaction".

In future research we propose to extend the GMUSA method to the fuzzy environment as future research in order to make the method capable of accepting and processing fuzzy scores as input and producing a utility function with fuzzy coefficients.

Open Access This article is distributed under the terms of the Creative Commons Attribution 4.0 International License (http://creativecommons.org/licenses/by/4.0/), which permits unrestricted use, distribution, and 
reproduction in any medium, provided you give appropriate credit to the original author(s) and the source, provide a link to the Creative Commons license, and indicate if changes were made.

\section{References}

Anghelache, V. (2014). Factors which determine the level of job satisfaction for Kindergarten teachers. Preliminary study. Procedia-Social and Behavioral Sciences, 127, 47-52.

Angilella, S., Corrente, S., Greco, S., \& Słowiński, R. (2014). MUSA-INT: Multicriteria customer satisfaction analysis with interacting criteria. Omega, 42(1), 189-200.

Aouadni, I., Rebaï, A., Christodoulakis, N., \& Siskos, Y. (2014). Job satisfaction measurement: The multicriteria satisfaction analysis. International Journal of Applied Decision Sciences, 7(2), 190-207.

Arqub, O. A., \& Abo-Hammour, Z. (2014). Numerical solution of systems of second-order boundary value problems using continuous genetic algorithm. Information Sciences, 279, 396-415.

Aslan, A. S., Shaukat, M. Z., Ahmed, I., Shah, I. M., \& Mahfar, M. (2014). Job satisfactions of academics in Malaysian public universities. Procedia-Social and Behavioral Sciences, 114, 154-158.

Badri, M. A., Mohaidat, J., Ferrandino, V., \& El Mourad, T. (2013). The social cognitive model of job satisfaction among teachers: Testing and validation. International Journal of Educational Research, 57, $12-24$.

Bellone, M., Merlino, M., \& Pesenti, R. (1995). ISPM: A DSS for personnel career management. Decision Support Systems, 15, 219-227.

Bernus, P., Blazewicz, J., Schmidt, G., \& Shaw, M. (Eds.). (2008). International handbooks on information systems. Springer.

Carsjens, G. J., \& Ligtenberg, A. A. (2007). A GIS-based support tool for sustainable spatial planning in metropolitan areas. Landscape and Urban Planning, 80, 72-83.

Chen, L. A. (2008). Job satisfaction among information system (1S) personnel. Computer in Human Behavior, $1,105-118$.

Constantopoulos, P. (1989). Decision support for massive personnel assignment. Decision Support Systems, 5, 353-363.

Demirel, H. (2014). An investigation of the relationship between job and life satisfaction among teachers. Procedia-Social and Behavioral Sciences, 116, 4925-4931.

Deng, X., Vroman, P., Zeng, X., \& Laouisset, B. (2010). Intelligent decision support tools for multicriteria product design. In Systems man and cybernetics (SMC), 2010 IEEE international conference on (pp. 1223-1230). IEEE.

Downey, D. B., \& Pribesh, S. (2004). When race matters: Teachers' evaluations of students' classroom behavior. Sociology of Education, 77, 267-282.

Duffy, R. D., \& Lent, R. W. (2009). Test of a social cognitive model of work satisfaction in teachers. Journal of Vocational Behavior, 75(2), 212-223.

Eom, H., \& Lee, S. (1990). Decision support systems applications research: A bibliography (1971-1988). European Journal of Operational Research, 46(3), 333-342.

Ernst, A. T., Jiang, H., Krishnamoorthy, M., \& Sier, D. (2004). Staff scheduling and rostering: A review of applications, methods and models. European Journal of Operational Research, 153(1), 3-27.

Farkas, G., Grobe, R. P., Sheehan, D., \& Shuan, Y. (1990). Cultural resources and school success: Gender, ethnicity, and poverty groups within an urban school district. American Sociological Review, 55(1), $127-142$.

Frye, W. D., \& Mount, D. J. (2007). An examination of job satisfaction of general managers based on hotel size and service type. Journal of Human Resources in Hospitality \& Tourism, 6, 109-134.

Goldberg, D. E. (1989). Genetic algorithms in search, optimization, and machine learning. Boston: AddisonWesley.

Grigoroudis, E., \& Siskos, Y. (2002). Preference disaggregation for measuring and analyzing customer satisfaction: The MUSA method. European Journal Operational Research, 143, 148-170.

Grigoroudis, E., \& Siskos, Y., (2003). MUSA: A decision support system for evaluating and analysing customer satisfaction. In Proceedings of the 9th Panhellenic conference in informatics (pp. 113-127). Thessaloniki, Greece

Grigoroudis, E., \& Siskos, Y. (2004). A survey of customer satisfaction barometers: Some results from the transportation-communications sector. European Journal of Operational Research, 152(2), 334-353.

Grigoroudis, E., \& Siskos, Y. (2009). Customer satisfaction evaluation: Methods for measuring and implementing service quality (Vol. 139). Berlin: Springer. 
Grigoroudis, E., Litos, C., Moustakis, V. A., Politis, Y., \& Tsironis, L. (2008). The assessment of user-perceived web quality: Application of a satisfaction benchmarking approach. European Journal of Operational Research, 187(3), 1346-1357.

Grigoroudis, E., Politis, Y., \& Siskos, Y. (2002). Satisfaction benchmarking and customer classification: An application to the branches of a banking organization. International Transactions in Operational Research, 9(5), 599-618.

Guglielmi, D., Panari, C., Simbula, S., \& Mazzetti, G. (2014). Is it possible to motivate teachers? The role of organizational identification. Procedia-Social and Behavioral Sciences, 116, 1842-1847.

Ingersoll, R., \& May, H. (2011a). The minority teacher shortage: Fact or fable? Phi Delta Kappan, 93(1), 62-65.

João, I. M., e Costa, C. A. B., \& Figueira, J. R. (2010). An ordinal regression method for multicriteria analysis of customer satisfaction. In Multiple criteria decision making for sustainable energy and transportation systems (pp. 167-176). Berlin, Heidelberg: Springer.

Karabiyik, B., \& Korumaz, M. (2014). Relationship between teacher's self-efficacy perceptions and job satisfaction level. Procedia-Social and Behavioral Sciences, 116, 826-830.

Klassen, R. M., \& Chiu, M. M. (2010). Effects on teachers' self-efficacy and job satisfaction: Teacher gender, years of experience, and job stress. Journal of Educational Psychology, 102(3), 741.

Koilias, C., Tourna, E., \& Koukouletsos, K. (2012). Job satisfaction of higher education graduates. Operational Research, 12(3), 421-437.

Lambert, E. G., Hogan, N. L., \& Griffin, M. L. (2007). Impact of distributive and procedural justice on correctional staff job stress, job satisfaction and organizational commitment. Journal of Criminal Justice, $5(6), 644-656$.

Lee, A. N., \& Nie, Y. (2014). Understanding teacher empowerment: Teachers' perceptions of principal's and immediate supervisor's empowering behaviours, psychological empowerment and work-related outcomes. Teaching and Teacher Education, 41, 67-79.

Lent, R. W., Nota, L., Soresi, S., Ginevra, M. C., Duffy, R. D., \& Brown, S. D. (2011). Predicting the job and life satisfaction of Italian teachers: Test of a social cognitive model. Journal of Vocational Behavior, 79, 91-97.

Limin, X., \& Yonggang, Z. (2009). Fuzzy evaluation on college teacher's job satisfaction based on improved algorithm. Second Asia-Pacific Conference on Computational Intelligence and Industrial Applications, 2, 189-192.

Mallach, E. G. (1994). Understanding decision support systems and expert systems. New York: McGraw-Hill.

McGrady, P. B., \& Reynolds, J. R. (2012). Racial mismatch in the classroom: Beyond blackwhite differences. Sociology of Education, 86(1), 3-17.

Mihaela, P. L. (2014). Psychological variables to professional satisfaction for teachers. Procedia-Social and Behavioral Sciences, 127, 807-811.

Mueller, Charles W., Finley, Ashley, Iverson, Roderick D., \& Price, James L. (1999). The effects of group racial composition on job satisfaction, organizational commitment, and career commitment: The case of teachers. Work and Occupations, 26, 187-219.

Ntuen, C. A., \& Chestnut, J. A. (1995). An expert system for selecting manufacturing workers for training. Expert System with Applications, 9(3), 309-332.

Ntuen, C. A., Winchester, W. W., Chestnut, J., \& Park, E. H. (1994). PASIM: A spreadsheet-based decision support system for performance analysis of production workers. Computers \& Industrial Engineering, 27(1-4), 1193-1196.

Nussbaum, M., Singer, M., Rosas, R., Castillo, M., Flies, E., Lara, R., et al. (1999). Decision support system for conflict diagnosis in personnel selection. Information \& Management, 36, 55-62.

Qian, Z., Huang, G. H., \& Chan, C. W. (2004). Development of an intelligent decision support system for air pollution control at coal-fired power plants. Expert System with Applications, 26(3), 335-356.

Razmak, J., \& Aouni, B. (2015). Decision support system and multi-criteria decision aid: A state of the art and perspectives. Journal of Multi-Criteria Decision Analysis, 22(1-2), 101-117.

Renzulli, L. A., Parrott, H. M., \& Beattie, I. R. (2011). Racial mismatch and school type teacher satisfaction and retention in charter and traditional public schools. Sociology of Education, 84(1), 23-48.

Siskos, Y., Grigoroudis, E., Krassadaki, E., \& Matsatsinis, N. (2007). A multicriteria accreditation system for information technology skills and qualifications. European Journal of Operational Research, 182, $867-885$.

Siskos, J. (1985). Analyses de régression et programmation linéaire. Revue de statistique appliquée, 33(1), 41-55.

Siskos, Y., \& Spyridakos, A. (1999). Intelligent multicriteria decision support: Overview and perspectives. European Journal of Operational Research, 113(2), 236-246. 
Siskos, Y., Matsatsinis, N. F., \& Baourakis, G. (2001). Multicriteria analysis in agricultural marketing: The case of French olive oil market. European Journal of Operational Research, 130(2), 315-331.

Skaalvik, E. M., \& Skaalvik, S. (2007). Dimensions of teacher self-efficacy and relations with strain factors, perceived collective teacher efficacy, and teacher burnout. Journal of Educational Psychology, 99, 611625.

Skaalvik, E. M., \& Skaalvik, S. (2011). Teacher job satisfaction and motivation to leave the teaching profession: Relations with school context, feeling of belonging, and emotional exhaustion. Teaching and Teacher Education, 27(6), 1029-1038.

Smith, P. C., Kendall, L. M., \& Hulin, C. L. (1969). The measurement of satisfaction in work and retirement. Chicago: Rand McNally.

Spilt, J. M., Koomen, M. Y., \& Thijs, J. T. (2011). Teacher wellbeing: The importance of teacher-student relationships. Educational Psychology Review, 23, 457-477.

Stearns, E., Banerjee, N., Mickelson, R., \& Moller, S. (2014). Collective pedagogical teacher culture, teacherstudent ethno-racial mismatch, and teacher job satisfaction. Social Science Research, 45, 56-72.

Super, D. E. (1957). The psychology of careers. New York: Harper.

Treputtharat, S., \& Tayiam, S. (2014). School climate affecting job satisfaction of teachers in primary education, Khon Kaen, Thailand. Procedia-Social and Behavioral Sciences, 116, 996-1000.

Turban, E., \& Aronson, J. (1998). Decision support systems and intelligent systems (5th ed.). Upper Saddle River: Prentice-Hall.

Van De Panne, C. (1975). A node method for multi-parametric linear programming. Management Science, 21(9), 1014-1020.

Veldman, I., van Tartwijk, J., Brekelmans, M., \& Wubbels, T. (2013). Job satisfaction and teacher-student relationships across the teaching career: Four case studies. Teaching and Teacher Education, 32, 55-65.

Wibowo, S., \& Deng, H., (2011). Intelligent decision support for criteria weighting in multicriteria analysis for evaluating and selecting cargo ships under uncertainty. In Proceedings of the international multiconference of 'engineers and computer scientists (Vol. 2).

Young, L. F. (1989). Decision support systems for workers: A bridge to advancing productivity. Information \& Management, 16(3), 131-140.

Zembylas, M., \& Papanastasiou, E. (2004). Job satisfaction among school teachers in Cyprus. Journal of Educational Administration, 42(3), 357-374. 